\title{
A NOTE ON THE STRLCTURE OF ACETYLENE
}

\section{BY ALBERT P. MATHEWS}

From a study of the volume of liquid acetylene, MacIntosh ${ }^{1}$ concluded that acetylene was in reality acetylidene since one of the carbon atoms seemed to have the volume of bivalent carbon. He supported this contention also by various chemical arguments. On the other hand, Nef," while showing that the halogen substitution products were in reality acetylidene compounds, beliered that acetylene was acetylene and not acetylidene, because it was chemically and physiologically so inert. Nef's pupil, Lawrie, ${ }^{3}$ confirmed the acetylidene nature of the bromine and iodine substitution products.

Although it is improbable, for the reasons stated by Nef, that acetylene is acetylidene, the matter may be definitely settled by my method of ${ }^{4}$ determining the number of valences in the molecule from the molecular cohesion. If it is acetylene there should be ten valences; if acetylidene, there should be eight, since acetylene does not associate and one carbon atom would be bivalent.

The most recent determination of the critical data of acetylene by Cardoso and Baumé gives $\mathrm{T}_{c}, 35.5^{\circ} \mathrm{C}$; and $\mathrm{P}_{c}$, 61.6 atmospheres. From these figures the value of " $a$ " of van der Waals' equation calculated by the formula: $a=$ $27_{c}^{2} 6+\times 273^{2} \times \mathrm{P}_{c}$, is $0.0087+5$. Computing the number of valences, $n$ from " $a$ " by the formula: $n=a^{3}=3.2 \times$

'MacIntosh: "The Physical Propertics of Liquid and Solid Acetylene," Jour. Phys. Chem., I I, 315 ( 1907$)$.

"Nef: "Ceber das zweiwertige Ǩohlenstufatom," Liebig's Ann., 298, 332 $(1897)$

"Lawrie: "Constitution of Acetylidene Compounds," Am. Chem. Jour., $36,+87-510(1006)$.

"Mathews: "The Relation of the Value ' $i$ ' uf van der Waals' Equation to Molecular Weight and the Number of Valences of the Molecule," Jour. Phys. Chem., I7, I8I (I9I3). 
I0: (Mol. Wt.), we obtain the value Io.o6 for $n$. There are, therefore, ten valences in the molecule of acetylene; accordingly each carbon has four, each hydrogen one.

Acetylene is, therefore, acetylene, as it is ordinarily written, and not acetylidene.

Lniversitu of Chicago 